\title{
Proximity of Premolar Roots to Maxillary Sinus: A Radiographic Survey Using Cone-beam Computed Tomography
}

\author{
Thomas von Arx, DMD, Ivo Fodich, DDS, and Michael M. Bornstein, DMD
}

\section{Ahstract}

Introduction: The proximity of the roots of the posterior maxillary teeth to the maxillary sinus is a constant challenge to the dental practitioner. Because the majority of studies have assessed the relationship regarding molars, the present study focused on premolars. Methods: Cone-beam computed tomographic images of 192 patients were reconstructed in sagittal, coronal, and axial planes to quantify the distances between the root apices of the maxillary premolars and the adjacent maxillary sinus. Measurements were taken for each root, and data were correlated with age, sex, side, and presence of both or absence of 1 of the 2 premolars. Results: A total of 296 teeth (177 first and 119 second premolars) were evaluated. The mean distances from buccal roots of the first premolars to the border of the maxillary sinus in the sagittal, coronal, and axial planes ranged from $5.15 \pm 2.99$ to $8.28 \pm 6.27 \mathrm{~mm}$. From palatal roots, the mean distances ranged from $4.20 \pm 3.69$ to $7.17 \pm 6.14 \mathrm{~mm}$. The mean distances of second premolars were markedly shorter in buccal roots between $2.32 \pm 2.19$ and $3.28 \pm 3.17 \mathrm{~mm}$ and in palatal roots between $2.68 \pm 3.58$ and $3.80 \pm 3.71 \mathrm{~mm}$, respectively. The frequency of a premolar root protrusion into the maxillary sinus was very low in first premolars $(0 \%-7.2 \%)$ but higher in second premolars $(2.5 \%-13.6 \%)$. Sex, age, side, and presence/absence of premolars failed to significantly influence the mean distances between premolar roots and the maxillary sinus. Conclusions: Based on the calculated mean distances of the present study, only few premolars (and if so second premolars) would present a risk of violating the border of the maxillary sinus during conventional or surgical endodontic treatment or in case of tooth extraction. (J Endod 2014;40:1541-1548)

\section{Key Words}

Cone-beam computed tomography, maxillary premolar, maxillary sinus

From the Department of Oral Surgery and Stomatology, School of Dental Medicine, University of Bern, Bern, Switzerland.

Address requests for reprints to Prof Thomas von Arx Department of Oral Surgery and Stomatology, School of Dental Medicine, University of Bern , Freiburgstrasse 7, CH-3010 Bern, Switzerland. E-mail address: thomas.vonarx@zmk.unibe.ch 0099-2399/\$ - see front matter

Copyright (๑) 2014 American Association of Endodontists. http://dx.doi.org/10.1016/j.joen.2014.06.022
The anatomic relationship between the teeth and the maxillary sinus has been a constant challenge in dentistry, in particular for nonsurgical and surgical endodontics as well as for extraction or surgical removal of posterior maxillary teeth (1-3). Furthermore, periradicular and periodontal pathoses originating from posterior maxillary teeth may spread into the maxillary sinus (4-8).

A very small maxillary sinus is present at birth, but it gradually increases in volume in adolescents and young adults. At about the age of 12 years, the sinus floor is level with the nasal floor. Around the age of 20 years, the floor of the maxillary sinus is situated $5 \mathrm{~mm}$ inferior to the nasal floor (9). A computed tomographic (CT) study reported that the growth of the maxillary sinus continues until the third decade in males and the second decade in females (10). Often, the floor of the maxillary sinus expands (sinus recesses) between the roots of the posterior teeth, resulting in a close proximity of roots and sinus. Radiographically, the roots may appear to penetrate the floor of the maxillary sinus and protrude into the antrum, but, in fact, it is the maxillary sinus that has extended around the roots (pneumatization of alveolar process).

In general, panoramic radiography is an unreliable method for determination of the topographic relationship between posterior teeth and the maxillary sinus $(3,11)$. Therefore, recent studies have focused on using CT $(4,12,13)$ or cone-beam computed tomographic (CBCT) imaging (14-18) for assessing the proximity between the roots and the sinus floor.

Some of the studies mentioned previously have limited their research to molars (4, $14,17)$. Therefore, the primary objective of the present study was to perform a detailed analysis of the radiographic relationship between the apices of maxillary premolars and the floor of the maxillary sinus using CBCT imaging. The secondary objective was to correlate the data with age, sex, side of evaluation, and status of premolars.

\section{Materials and Methods}

CBCT images of the maxilla taken in our department from October 2012 to July 2013 were retrospectively evaluated. Because of the retrospective nature of the evaluation, the study was exempt from formal approval by the institutional review board. Because the present study focused on the relationship between premolars and the maxillary sinus, only cases showing the area of the maxillary premolars (region of interest $[\mathrm{ROI}]$ ) were included in this survey. Cases presenting with the following findings were excluded from further analysis:

1. Premolars showing periapical or periradicular lesions

2. Status after sinus floor elevation

3. Foreign material in the ROI

4. Images with artifacts such as motion, beam hardening or scatter

A total of 202 CBCT images taken in 192 patients fulfilled the inclusion criteria. The CBCT images were obtained with a 3D Accuitomo XYZ Slice View Tomograph (Morita, Kyoto, Japan) with fields of view (FOVs) varying between $16 \mathrm{~cm}^{2}(4 \times 4$ $\mathrm{cm})$ and $140 \mathrm{~cm}^{2}(10 \times 14 \mathrm{~cm})$, and basic voxel sizes varying between $0.08 \mathrm{~mm}$ and $0.25 \mathrm{~mm}$. Operating parameters were set at $5.0 \mathrm{~mA}$ and $90 \mathrm{kV}$ and exposure times of 10.5 (high-speed modus) or 17.5 seconds (standard modus). For all CBCT images, the FOV was selected according to the clinical situation and the planned therapy; the FOVs were grouped into small $\left(<40 \mathrm{~cm}^{2}\right)$, medium $\left(40-100 \mathrm{~cm}^{2}\right)$, and large/ 


\section{Clinical Research}
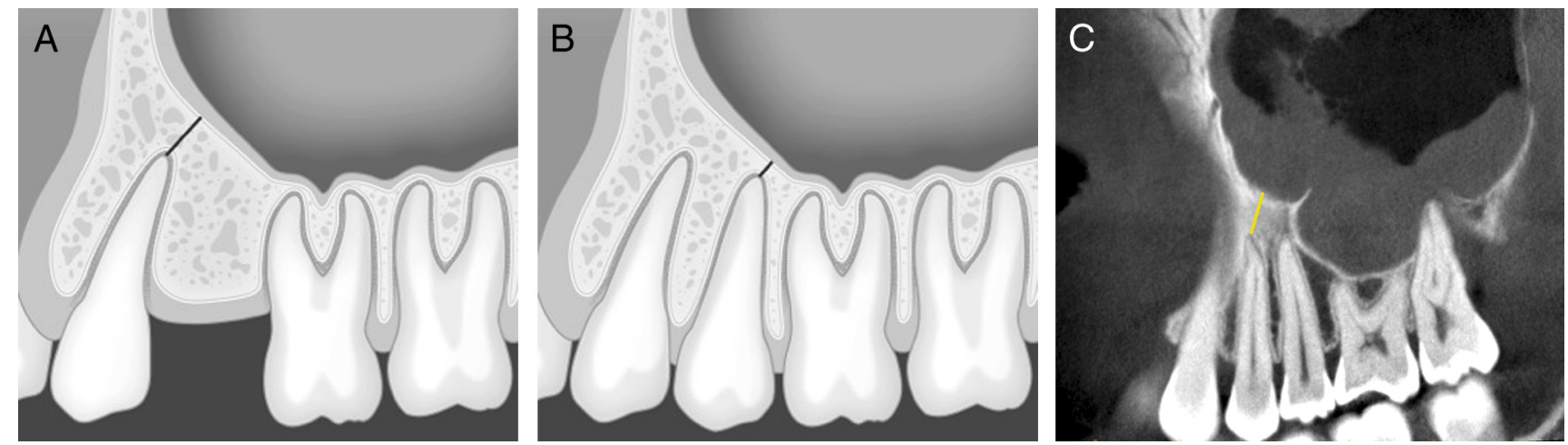

Figure 1. (A) A schematic illustration of the measurement of the shortest distance from the first premolar to the floor of the maxillary sinus (sagittal plane). (B) A schematic illustration of the measurement of the shortest distance from the second premolar to the floor of the maxillary sinus (sagittal plane). $(C)$ A sagittal CBCT view showing the shortest distance from the first premolar to the floor of the maxillary sinus.

maxillofacial $\left(>100 \mathrm{~cm}^{2}\right)$. The data were reconstructed with slices at an interval of $0.5 \mathrm{~mm}$, which were positioned parallel to the horizontal plane of the posterior maxillary alveolar crest. Subsequently, the roots of the premolars were identified, and for each root, the sagittal, coronal, and axial planes for measurements were determined as follows:

1. Sagittal image: Through the central long axis of the root (anteroposterior orientation)

2. Coronal image: Through the central long axis of the root (mediolateral orientation)

3. Axial image: Through the apex of the root (horizontal orientation)

The CBCT images were evaluated on a Dell 380 Precision workstation (Dell SA, Geneva, Switzerland) and a 19-inch Eizo Flexscan monitor with a resolution of $1280 \times 1024$ pixels (Eizo Nanao AG, Wädenswil, Switzerland). The following analyses and measurements (primary objectives) were performed using specialized computer software (i-Dixel, Version 2.0.4, Morita):

1. Shortest vertical/oblique distance from the root apex of any buccal, palatal, or accessory root of first and second premolars to the closest border of the maxillary sinus (sagittal views [Fig. $1 A-C$ ] and coronal views [Fig. $2 A-C$ ]) (negative value if the root tip was located above the floor of the maxillary sinus)

2. Shortest horizontal distance from the root apex of any buccal, palatal, or accessory root of first and second premolars to the closest border of the maxillary sinus (axial view [Fig. 3A-C]) (negative value if the root tip was located inside the border of the maxillary sinus)

In addition, the sex and age of each patient were recorded as well as the side of evaluation and the presence/absence of 1 of the 2 premolars to correlate these data with the obtained radiographic measurements (secondary objectives).

\section{Statistics}

All data were first analyzed descriptively. To detect significant differences between distances of the buccal versus palatal premolar apices to the border of the maxillary sinus for sagittal, coronal, and axial CBCT scans, nonparametric longitudinal analysis of variance analyses were used. To detect significant differences between the distances of the
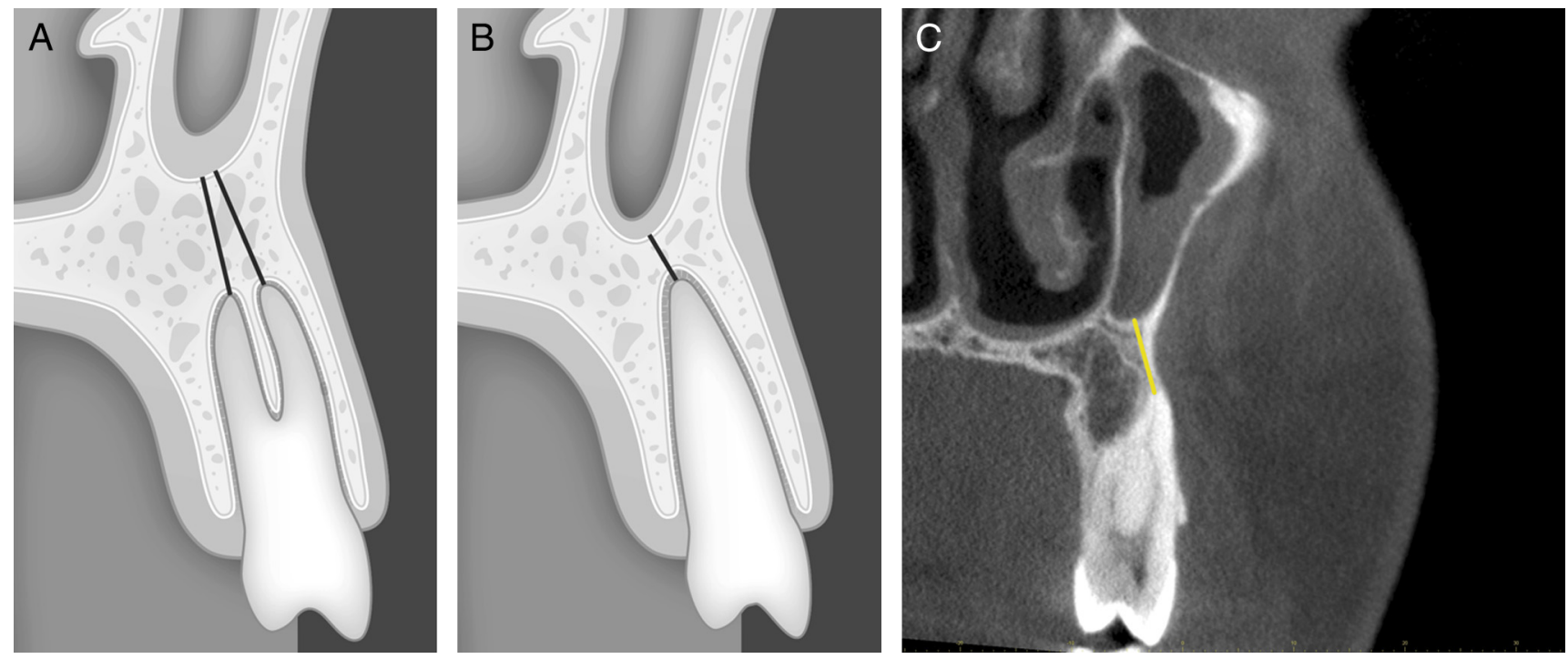

Figure 2. (A) A schematic illustration of the measurement of the shortest distance from both roots of the first premolar to the floor of maxillary sinus (coronal plane). (B) A schematic illustration of the measurement of the shortest distance from the second premolar to the floor of the maxillary sinus (coronal plane). (C) A coronal CBCT view showing the shortest distance from the first premolar to the floor of the maxillary sinus. 

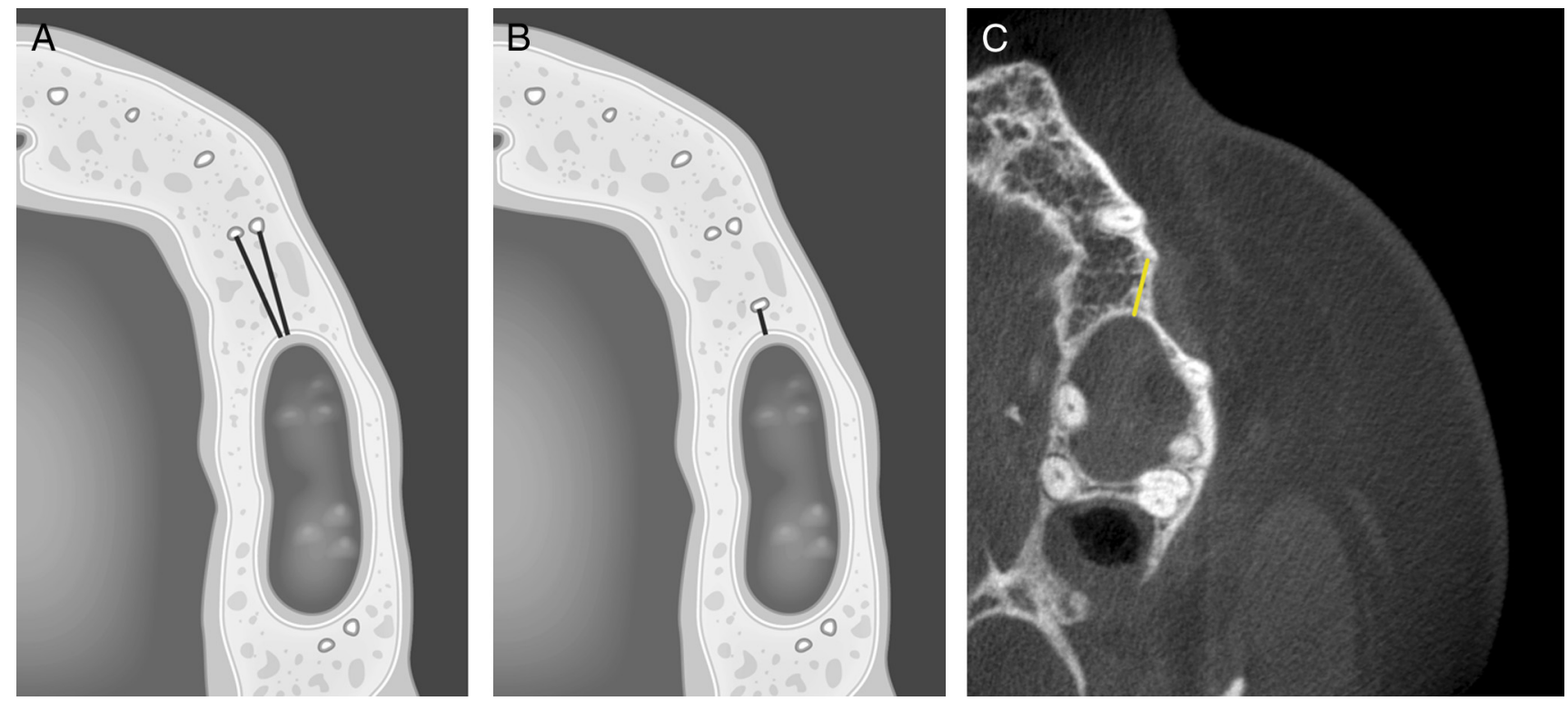

Figure 3. (A) A schematic illustration of the measurement of the shortest distance from both roots of the first premolar to the floor of the maxillary sinus (axial plane). (B) A schematic illustration of the measurement of the shortest distance from the second premolar to the floor of the maxillary sinus (axial plane). (C) An axial CBCT view showing the shortest distance from the first premolar to the floor of the maxillary sinus.

premolar apices (pooled data sets) to the border of the maxillary sinus and sex, age, side of evaluation, and presence/absence of 1 of the 2 premolars, nonparametric analysis of variance analysis was performed for longitudinal data according to the method described by Brunner et al (19). For the statistical analysis of the frequency of root positions relative to the sinus, Fisher exact tests were used. The analyses were explorative in nature; thus, no correction for multiple testing was applied. For the statistical analysis, the Internet-based R software package ( $\mathrm{R} 2.15 .1$; http://www.r_project.org; The R Foundation for Statistical Computing, Vienna, Austria) was used. Furthermore, the extension packages exactRankTests and nparLD were used.

\section{Results}

A total of 296 premolars were assessed in 192 patients (males: $42.7 \%$, females: $57.3 \%$ ) who had a mean age of $58.4 \pm 20.5$ years (range, $19-81$ years). The evaluation per situations $(n=202)$ showed that both premolars were present $(46.5 \%)$, only the first premolar was present $(41.1 \%)$, or only the second premolar was present $(12.4 \%)$ (Table 1). Among the evaluated premolars, 59.8\% were first premolars, and $40.2 \%$ were second premolars (Table 2). A total of 407 roots were observed with 405 analyzed roots. The most frequently assessed roots were buccal roots of first premolars (43.5\%). Two first premolars each presented an accessory buccal root (Table 3), which were excluded in the present analysis.

\section{Primary Objectives}

In the sagittal plane, the mean distances from the buccal and palatal roots of the first premolars to the floor of the maxillary sinus were

TABLE 1. Distribution of Evaluated Situations $(n=202)$

\begin{tabular}{lcrr}
\hline & $\begin{array}{c}\text { Right } \\
\text { side }\end{array}$ & $\begin{array}{r}\text { Left } \\
\text { side }\end{array}$ & Total (\%) \\
\hline Only first premolar present & 40 & 43 & $83(41.1)$ \\
Only second premolar present & 11 & 14 & $25(12.4)$ \\
Both premolars present & 44 & 50 & $94(46.5)$ \\
Total & 95 & 107 & $202(100)$ \\
\hline
\end{tabular}

$5.15 \pm 2.99 \mathrm{~mm}$ and $4.20 \pm 3.69 \mathrm{~mm}$, respectively (Tables 4-6). The palatal roots were about $1 \mathrm{~mm}$ closer to the maxillary sinus floor than the buccal roots, which was statistically significant $(P=.002)$. The values for the second premolars were $2.32 \pm 2.19 \mathrm{~mm}$ and $2.68 \pm 3.58 \mathrm{~mm}$, respectively $(P=.86)$. In the coronal plane, the mean distances from the buccal and palatal roots of the first premolars to the floor of the maxillary sinus were $8.28 \pm 6.27 \mathrm{~mm}$ and $7.17 \pm 6.14 \mathrm{~mm}$, respectively. The palatal roots were again about $1 \mathrm{~mm}$ closer to the maxillary sinus floor than the buccal roots $(P=.08)$. The values for the second premolars were $3.28 \pm 3.17 \mathrm{~mm}$ and $3.69 \pm 4.51 \mathrm{~mm}$, respectively $(P=.89)$. In the axial plane, the mean distances from the buccal and palatal roots of the first premolars to the floor of the maxillary sinus were $5.86 \pm 3.54 \mathrm{~mm}$ and $5.71 \pm 3.89 \mathrm{~mm}$, respectively $(P=.86)$. The values for the second premolars were $2.40 \pm 2.71 \mathrm{~mm}$ and $3.80 \pm 3.71 \mathrm{~mm}$, respectively $(P=.07)$.

\section{Secondary Objectives}

In males, premolar roots were on average situated closer to the maxillary sinus than in females irrespective of the assessed root and the CBCT plane but without reaching statistical significance $(P=.19$ for sagittal values; $P=.32$ for coronal values; $P=.11$ for axial values) (Tables 7 and 8). Regarding age, no consistent pattern was observed for the minimum distances between root apices and the border of the maxillary sinus comparing the mean values of the different age groups ( $P=.11$ for sagittal values, $P=.24$ for coronal values, and $P=.10$ for axial values). With respect to the side analysis, mean distances on the patient's right side tended to be greater in the sagittal plane but shorter in the other planes compared with the left

TABLE 2. Distribution of Evaluated Premolars $(n=296)$

\begin{tabular}{lccl}
\hline & Right side & Left side & Total $(\%)$ \\
\hline First premolars & 84 & 93 & $177(59.8)$ \\
Second premolars & 55 & 64 & $119(40.2)$ \\
Total & 139 & 157 & $296(100)$ \\
\hline
\end{tabular}


TABLE 3. Distribution of Evaluated Roots $(n=407)$

\begin{tabular}{lccc}
\hline & Right side & Left side & Total (\%) \\
\hline First premolar & & & \\
Buccal root & 84 & 93 & $177(43.5)$ \\
Palatal root & 41 & 43 & $84(20.6)$ \\
Accessory root & 1 & 1 & $2(0.5)$ \\
Second premolar & & & \\
Buccal root & 55 & 64 & $119(29.2)$ \\
Palatal root & 16 & 9 & $25(6.1)$ \\
Accessory root & - & - & - \\
Total & 197 & 210 & $407(100 \%)$ \\
\hline
\end{tabular}

side. Yet, the differences were not statistically significant $(P=.68$ for sagittal values, $P=.17$ for coronal values, and $P=.63$ for axial values). Concerning the presence or absence of premolars, the mean distances tended to be greater if both premolars were present but without reaching statistical significance $(P=.20$ for sagittal values, $P=.86$ for coronal values, and $P=.57$ for axial values). Descriptively, the following constant findings were observed: when the second premolar was missing, the mean distances between root apices of first premolars and the sinus floor were always shorter (irrespective of the CBCT plane) compared with the situation with both premolars present (differences of means ranged between 0.49 and $1.0 \mathrm{~mm}$ ). In contrast, when the first premolar was missing, the mean distances between the root apices of second premolars and the sinus floor were always greater (irrespective of the CBCT plane) compared with the situation with both premolars present (differences of means ranged between 1.24 and $1.68 \mathrm{~mm}$ ).

\section{Frequency Analysis}

The majority of first premolar buccal apices $(97.7 \%-99.3 \%)$ and palatal apices $(92.2 \%-92.9 \%)$ were located outside of the confines of the maxillary sinus (Tables 9 and 10). The corresponding percentages were lower in second premolars (89\%-94.1\% for buccal apices and $76.0 \%-86.4 \%$ for palatal apices, respectively). Significant differences were found comparing the location of palatal versus buccal roots of the first premolars relative to the sinus border in coronal $(P=.03)$ and axial planes $(P=.01)$ but not in sagittal planes $(P=.08)$. For the second premolars, the location of palatal versus buccal roots of the first premolars relative to the sinus border was significantly different for sagittal $(P=.02)$ and coronal planes $(P=.02)$ but not for axial planes $(P=.72)$. When comparing the first with the second premolars, the location of buccal roots exhibited statistically significant differences only in axial planes $(P=.003)$ but not in sagittal $(P=.07)$ and coronal planes $(P=.08)$. For palatal roots, only sagittal planes were significantly different $(P=.03)$, but neither coronal $(P=.12)$ nor axial planes $(P=.39)$.

\section{Discussion}

The present radiographic study aimed at measuring the distances between the root apices of maxillary premolars and the floor of the maxillary sinus using reformatted CBCT images. Premolars have traditionally not attracted the same attention compared with molars regarding their proximity to the floor of the sinus. That may be explained by the fact that teeth most frequently associated with oroantral communication in exodontia are first or second molars $(1,20)$. However, several studies have documented the mesial extension of the maxillary sinus above or even beyond the first premolar, highlighting the possibility of a close relationship also between premolars and the floor of the antrum $(21,22)$. Kim et al $(21)$ assessed the mesial extension of the maxillary sinus in 33 hemisectioned cadaver heads using CT reformatted panoramic views of 24 sides. In $58 \%$ of specimens, the anterior limit of the maxillary sinus was located in the first premolar area, in 33\% in the canine area, and in $8 \%$ in the second premolar area. Kopecka et al (22) evaluated 583 panoramic radiographs of edentulous maxillae. In 14 cases $(2.4 \%)$, the anterior border of the maxillary sinus was above the canine, in 565 cases $(96.9 \%)$ it was above the first premolar, and in the remaining 4 cases $(0.7 \%)$ it was above the second premolar.

Analyzing the data regarding measurements between the premolar roots and the floor of the maxillary sinus floor, the following statements can be made:

1. The mean distances of first premolars were always greater than those of second premolars irrespective of the root, side, or plane (except the comparison of palatal roots in the axial plane on the left side, but $n=7$ was low). The greatest difference of any data set amounted to $5.60 \mathrm{~mm}$ comparing buccal roots of the first and second left premolars in the coronal plane $(8.57 \mathrm{~mm}$ vs $2.97 \mathrm{~mm})$.

2. In the first premolars, palatal roots were always located closer to the sinus than buccal roots in any plane. In second premolars, the same finding was observed on the right sides, but on the left sides the palatal roots were located further away from the sinus than the buccal roots. This might be explained by the fact that some of the palatal roots of the left second premolars were very short.

3. Measurements obtained in the coronal planes were always greater than those in the sagittal planes for all roots and sides. This is explained by the fact that usually the most inferior point of the maxillary sinus is located in the first molar area with the sinus floor gradually ascending anteriorly over the premolars. Thus, the shortest distance from the apex to the sinus on the sagittal image was mostly taken in an oblique direction, but the corresponding coronal section was perpendicular relative to the sagittal section, explaining the higher values of measurements obtained with coronal images.

4. The same observation was made comparing axial and sagittal measurements with higher values in the axial plane (except for the left

TABLE 4. Measurements of Distances $(\mathrm{mm})$ between the Apices of Premolar Roots and the Maxillary Sinus in the Sagittal Plane $(n=405)$

\begin{tabular}{|c|c|c|c|c|c|c|c|c|c|c|c|c|}
\hline & \multicolumn{4}{|c|}{ Right side } & \multicolumn{4}{|c|}{ Left side } & \multicolumn{4}{|c|}{ All } \\
\hline & $N$ & Mean \pm SD & Min & Max & $N$ & Mean \pm SD & Min & Max & $N$ & Mean \pm SD & Min & Max \\
\hline \multicolumn{13}{|l|}{ First premolar } \\
\hline Buccal root & 84 & $5.32 \pm 3.27$ & -1.32 & 17.16 & 93 & $4.99 \pm 2.72$ & -1.51 & 11.10 & 177 & $5.15^{*} \pm 2.99$ & -1.51 & 17.16 \\
\hline Palatal root & 41 & $4.19 \pm 3.74$ & -0.92 & 13.96 & 43 & $4.21 \pm 3.68$ & -2.11 & 15.37 & 84 & $4.20 * \pm 3.69$ & -2.11 & 15.37 \\
\hline \multicolumn{13}{|c|}{ Second premolar } \\
\hline Buccal root & 55 & $2.46 \pm 2.12$ & -1.38 & 8.61 & 64 & $2.20 \pm 2.26$ & -1.85 & 11.87 & 119 & $2.32 \pm 2.19$ & -1.85 & 11.87 \\
\hline Palatal root & 16 & $1.24 \pm 2.99$ & -4.71 & 5.21 & 9 & $4.13 \pm 3.97$ & 0 & 12.59 & 25 & $2.68 \pm 3.58$ & -4.71 & 12.59 \\
\hline
\end{tabular}

SD, standard deviation.

$* P=.002$. 
Clinical Research

TABLE 5. Measurements of Distances ( $\mathrm{mm})$ between the Apices of Premolar Roots and the Maxillary Sinus in the Coronal Plane $(n=346)$

\begin{tabular}{|c|c|c|c|c|c|c|c|c|c|c|c|c|}
\hline & \multicolumn{4}{|c|}{ Right side } & \multicolumn{4}{|c|}{ Left side } & \multicolumn{4}{|c|}{ All } \\
\hline & $N$ & Mean \pm SD & Min & Max & $N$ & Mean \pm SD & Min & Max & $N$ & Mean \pm SD & Min & Max \\
\hline \multicolumn{13}{|l|}{ First premolar } \\
\hline Buccal root & 67 & $7.94 \pm 6.26$ & 0 & 26.15 & 74 & $8.57 \pm 6.3$ & 0 & 21.93 & 141 & $8.28 \pm 6.27$ & 0 & 26.15 \\
\hline Palatal root & 33 & $6.84 \pm 6.08$ & -0.74 & 24.74 & 31 & $7.51 \pm 6.38$ & 0.92 & 21.88 & 64 & $7.17 \pm 6.14$ & -0.74 & 24.74 \\
\hline \multicolumn{13}{|c|}{ Second premolar } \\
\hline Buccal root & 55 & $3.63 \pm 3.70$ & 0.49 & 16.09 & 63 & $2.97 \pm 2.77$ & -1.35 & 13.93 & 118 & $3.28 \pm 3.17$ & -1.35 & 16.09 \\
\hline Palatal root & 15 & $3.03 \pm 4.74$ & -3.03 & 14.48 & 8 & $4.94 \pm 4.26$ & 0.81 & 13.25 & 23 & $3.69 \pm 4.51$ & -3.03 & 14.48 \\
\hline
\end{tabular}

SD, standard deviation.

TABLE 6. Measurements of Distances (mm) between the Premolar Roots and the Maxillary Sinus in the Axial Plane $(n=330)$

\begin{tabular}{|c|c|c|c|c|c|c|c|c|c|c|c|c|}
\hline & \multicolumn{4}{|c|}{ Right side } & \multicolumn{4}{|c|}{ Left side } & \multicolumn{4}{|c|}{ All } \\
\hline & $N$ & Mean \pm SD & Min & $\operatorname{Max}$ & $N$ & Mean \pm SD & Min & Max & $N$ & Mean \pm SD & Min & Max \\
\hline \multicolumn{13}{|l|}{ First premolar } \\
\hline Buccal root & 67 & $5.85 \pm 3.51$ & -0.87 & 15.77 & 81 & $5.86 \pm 3.47$ & 0.68 & 17.39 & 148 & $5.86 \pm 3.54$ & -0.87 & 17.39 \\
\hline Palatal root & 33 & $5.69 \pm 3.96$ & -0.68 & 14.49 & 36 & $5.72 \pm 3.89$ & -1.49 & 17.42 & 69 & $5.71 \pm 3.89$ & -1.49 & 17.42 \\
\hline \multicolumn{13}{|c|}{ Second premolar } \\
\hline Buccal root & 40 & $2.87 \pm 2.75$ & -1.27 & 14.01 & 51 & $2.12 \pm 2.71$ & -1.21 & 16.38 & 91 & $2.40 \pm 2.71$ & -1.27 & 16.38 \\
\hline Palatal root & 15 & $2.84 \pm 3.71$ & -1.68 & 8.17 & 7 & $5.74 \pm 3.98$ & 2.03 & 14.54 & 22 & $3.80 \pm 3.71$ & -1.68 & 14.54 \\
\hline
\end{tabular}

SD, standard deviation.

TABLE 1. Measurements of Distances (mm) in the First Premolars with Respect to the Secondary Study Parameters

\begin{tabular}{|c|c|c|c|c|c|c|c|c|c|c|c|c|}
\hline & \multicolumn{4}{|c|}{ Sagittal plane } & \multicolumn{4}{|c|}{ Coronal plane } & \multicolumn{4}{|c|}{ Axial plane } \\
\hline & $N$ & Mean \pm SD & Min & Max & $N$ & Mean \pm SD & Min & Max & $N$ & Mean \pm SD & Min & Max \\
\hline \multicolumn{13}{|l|}{ Sex } \\
\hline Male & 74 & $4.29 \pm 2.76$ & -1.32 & 11.91 & 63 & $7.70 \pm 6.55$ & 0 & 23.90 & 66 & $5.36 \pm 3.55$ & -0.87 & 15.77 \\
\hline Female & 103 & $5.10 \pm 3.15$ & -1.81 & 15.56 & 79 & $8.53 \pm 6.27$ & 0.18 & 26.15 & 83 & $5.98 \pm 3.54$ & 0.1 & 17.40 \\
\hline \multicolumn{13}{|l|}{ Age } \\
\hline$\leq 20 y$ & 1 & 1.54 & 1.54 & 1.54 & 1 & 0.74 & 0.74 & 0.74 & 1 & 2.02 & 2.02 & 2.02 \\
\hline $21-40 y$ & 17 & $5.27 \pm 3.97$ & 0.13 & 15.56 & 13 & $9.05 \pm 5.21$ & 0.40 & 19.2 & 14 & $5.12 \pm 3.47$ & 0.88 & 12.38 \\
\hline $41-60 y$ & 78 & $4.31 \pm 2.8$ & -1.81 & 10.62 & 70 & $8.36 \pm 6.52$ & 0 & 23.99 & 65 & $5.41 \pm 3.43$ & -0.87 & 15.77 \\
\hline$>60 y$ & 81 & $5.15 \pm 2.94$ & 0 & 11.91 & 58 & $7.85 \pm 6.40$ & 0 & 26.15 & 69 & $6.15 \pm 3.63$ & 0.13 & 17.40 \\
\hline \multicolumn{13}{|l|}{ Side } \\
\hline Right & 84 & $4.86 \pm 3.00$ & -1.32 & 15.56 & 67 & $7.72 \pm 6.34$ & 0 & 26.15 & 68 & $5.67 \pm 3.58$ & -0.87 & 15.77 \\
\hline Left & 93 & $4.67 \pm 3.01$ & -1.81 & 12.01 & 75 & $8.52 \pm 6.39$ & 0 & 21.90 & 81 & $5.73 \pm 3.53$ & 0.1 & 17.40 \\
\hline \multicolumn{13}{|c|}{ Presence/absence of premolars } \\
\hline Both premolars present & 94 & $5.07 \pm 3.00$ & 0 & 15.56 & 73 & $8.74 \pm 6.34$ & 0 & 23.99 & 79 & $5.93 \pm 3.54$ & 0.13 & 17.40 \\
\hline $\begin{array}{l}\text { Second premolar } \\
\text { missing }\end{array}$ & 83 & $4.42 \pm 2.99$ & -1.81 & 11.91 & 69 & $7.54 \pm 6.3$ & 0 & 26.15 & 70 & $5.44 \pm 3.47$ & -0.87 & 15.77 \\
\hline
\end{tabular}

SD, standard deviation.

buccal roots of the second premolars), showing that the maxillary sinus is closer to the premolar apices in the vertical than in the horizontal dimension.

5. Comparing coronal and axial measurements, coronal values were always higher than axial values except for the left and overall palatal roots of the second premolars, reflecting the fact that the maxillary sinus moves away from the root apices (pyramidal shape of maxillary sinus with its base medially [lateral wall of nasal cavity] and its apex laterally [zygomatic bone]).

Previous radiographic studies providing data about the position of posterior roots relative to the floor of the maxillary sinus have used panoramic radiographs (16), CT scans $(4,12,13)$, or CBCT imaging (14-18) (Table 11). However, the reliability of panoramic radiography in the prediction of root position/root projection of posterior maxillary teeth with respect to the maxillary sinus has been shown to be doubtful
$(3,11)$. Sharan and Madjar (11) compared paired panoramic radiographs and CT scans of 80 subjects regarding the concordance of root position (second premolars and first and second molars) relative to the sinus floor. Only $39 \%$ of the roots that projected on the sinus cavity in panoramic radiographs also showed protrusion into the sinus with CT imaging. (For second premolars, the rate was 33.3\%.) The mean projection length in the panoramic radiographs was $3.1 \pm 2.54 \mathrm{~mm}$ compared with $1.5 \pm 1.50 \mathrm{~mm}$ in CT scans $(P<.001)$.

Of the summarized studies in Table 11, only few investigations have provided metric measurements for premolar distances to be compared with the data of the present study. In fact, only 2 studies used a similar methodology (CBCT imaging) to measure the distances between premolar roots and the sinus floor $(15,16)$. Kilic et al (15) used coronal CBCT planes and reported a mean distance of $8.42 \mathrm{~mm}$ (right side) and $6.58 \mathrm{~mm}$ (left side) for first premolars and $3.75 \mathrm{~mm}$ (right side) and $3.73 \mathrm{~mm}$ (left side) for second premolars. However, as shown 
TABLE 8. Measurements of Distances (mm) in the Second Premolars with Respect to the Secondary Study Parameters

\begin{tabular}{|c|c|c|c|c|c|c|c|c|c|c|c|c|}
\hline & \multicolumn{4}{|c|}{ Sagittal plane } & \multicolumn{4}{|c|}{ Coronal plane } & \multicolumn{4}{|c|}{ Axial plane } \\
\hline & $N$ & Mean \pm SD & Min & Max & $N$ & Mean \pm SD & Min & Max & $N$ & Mean \pm SD & Min & Max \\
\hline \multicolumn{13}{|l|}{ Sex } \\
\hline Male & 53 & $2.1 \pm 2.18$ & -2.13 & 12.23 & 52 & $2.98 \pm 3.20$ & -1.35 & 16.09 & 44 & $2.12 \pm 2.64$ & -1.21 & 15.46 \\
\hline Female & 66 & $2.32 \pm 2.19$ & -1.86 & 8.61 & 66 & $3.51 \pm 3.20$ & -1.21 & 14.12 & 47 & $2.64 \pm 2.66$ & -1.25 & 14.01 \\
\hline \multicolumn{13}{|l|}{ Age } \\
\hline$\leq 20 y$ & - & - & - & - & - & - & - & - & - & - & - & - \\
\hline $21-40$ y & 13 & $1.82 \pm 2.46$ & -2.13 & 8.61 & 13 & $3.75 \pm 4.10$ & 0.65 & 14.12 & 9 & $1.39 \pm 1.68$ & -0.95 & 5.42 \\
\hline $41-60 y$ & 59 & $2.0 \pm 2.00$ & -1.86 & 7.42 & 59 & $2.72 \pm 2.81$ & -1.35 & 16.09 & 46 & $2.05 \pm 1.95$ & -1.25 & 8.59 \\
\hline$>60 y$ & 47 & $2.58 \pm 2.27$ & -1.85 & 12.23 & 46 & $3.86 \pm 3.24$ & 0 & 13.59 & 36 & $3.07 \pm 3.35$ & -0.84 & 15.46 \\
\hline \multicolumn{13}{|l|}{ Side } \\
\hline Right & 55 & $2.33 \pm 2.20$ & -2.13 & 8.61 & 55 & $3.72 \pm 3.22$ & -1.21 & 16.09 & 40 & $2.76 \pm 2.69$ & -1.25 & 14.01 \\
\hline Left & 64 & $2.14 \pm 2.19$ & -1.85 & 12.23 & 63 & $2.90 \pm 3.21$ & 1.35 & 13.59 & 51 & $2.10 \pm 2.65$ & -1.21 & 15.46 \\
\hline \multicolumn{13}{|c|}{ Presence/absence of premolars } \\
\hline Both premolars present & 94 & $1.90 \pm 2.19$ & -2.13 & 8.61 & 94 & $2.94 \pm 3.21$ & 1.35 & 16.09 & 75 & $2.17 \pm 2.65$ & -1.25 & 15.46 \\
\hline First premolar missing & 25 & $3.45 \pm 2.22$ & 1.15 & 12.23 & 24 & $4.62 \pm 3.36$ & 0.46 & 13.59 & 16 & $3.41 \pm 2.78$ & -0.87 & 8.74 \\
\hline
\end{tabular}

SD, standard deviation.

in the present study, the use of only coronal measurements may provide overestimated distances and not the true shortest distance between the root apex and sinus floor. Georgescu et al (16) only included premolars with fused roots and measured the distances on reformatted panoramic and cross-sectional CBCT images. The mean distances between first premolars and the sinus floor amounted to $6.35 \mathrm{~mm}$ (panoramic view) and $7.56 \mathrm{~mm}$ (cross section), and between the second premolars and the sinus floor, it was $4.5 \mathrm{~mm}$ (panoramic view) and $4.64 \mathrm{~mm}$ (cross-section), respectively. These data also confirm the higher values obtained in coronal (cross-section) compared with sagittal (panoramic) planes.

Metric measurements between maxillary roots and adjacent anatomic structures obtained with CBCT imaging are considered accurate. Howe (14) assessed the concordance of CBCT and gross dissection measurements for dimensions of maxillary bone in 69 maxillary first molars of 37 cadaver specimens. The data sets displayed a Pearson correlation coefficient of $r=0.85$ with a positive bias for CBCT imaging of $0.4 \mathrm{~mm}$.

Regarding the frequency of a premolar root protruding into the maxillary sinus, Sharan and Madjar (11) reported such a finding in $8.3 \%$ of second premolars for coronal CT scans. (The first premolars

TABLE 9. Frequency Analysis of the Root Position of the First Premolars with Respect to the Border of the Maxillary Sinus

\begin{tabular}{|c|c|c|c|c|c|c|}
\hline & \multicolumn{2}{|c|}{$\begin{array}{l}\text { Sagittal } \\
\text { plane }\end{array}$} & \multicolumn{2}{|c|}{$\begin{array}{l}\text { Coronal } \\
\text { plane* }\end{array}$} & \multicolumn{2}{|c|}{$\begin{array}{l}\text { Axial } \\
\text { plane* }\end{array}$} \\
\hline & $N$ & $\%$ & $N$ & $\%$ & $N$ & $\%$ \\
\hline \multicolumn{7}{|l|}{ Buccal roots } \\
\hline $\begin{array}{l}\text { Root tip below/outside } \\
\text { border of MS }\end{array}$ & 173 & 97.7 & 140 & 98.6 & 147 & 99.3 \\
\hline Root tip at border of MS & 1 & 0.6 & 2 & 1.4 & 0 & 0 \\
\hline $\begin{array}{l}\text { Root tip above/inside } \\
\text { border of MS }\end{array}$ & 3 & 1.7 & 0 & 0 & 1 & 0.7 \\
\hline Total & 177 & 100 & 142 & 100 & 148 & 100 \\
\hline \multicolumn{7}{|l|}{ Palatal roots } \\
\hline $\begin{array}{l}\text { Root tip below/outside } \\
\text { border of MS }\end{array}$ & 78 & 92.9 & 59 & 92.2 & 64 & 92.8 \\
\hline Root tip at border of MS & 1 & 1.2 & 2 & 3.1 & 0 & 0 \\
\hline $\begin{array}{l}\text { Root tip above/inside } \\
\text { border of MS }\end{array}$ & 5 & 5.9 & 3 & 4.7 & 5 & 7.2 \\
\hline Total & 84 & 100 & 64 & 100 & 69 & 100 \\
\hline
\end{tabular}

MS, maxillary sinus.

*The distribution of the percentages comparing buccal and palatal roots was statistically significantly different in the coronal plane $(P=.03)$ and in the axial plane $(P=.01)$. were not evaluated.) Much lower figures were reported for root protrusions of first ( $0 \%)$ and second premolars (0.9\%) in a CBCT study of 50 patients (18). In the present study, the first premolar roots protruded into the sinus cavity in $0 \%-0.6 \%$ of buccal roots and in $0 \%-3.1 \%$ of palatal roots depending on the reformatted CBCT plane. Root protrusions of second premolars were observed more frequently with $2.5 \%-7.7 \%$ in buccal and $8.7 \%-13.6 \%$ in palatal roots, respectively.

Comparing the calculated mean distances and the secondary study parameters, no statistically significant correlations were found. However, males tended to have their premolar roots closer to the maxillary sinus compared with females. This observation may be explained by the fact that premolar roots are generally longer in males than in females, and the maxillary sinus on average presents larger dimensions in males than in females $(21,23,24)$. An invariable observation was that the absence of 1 premolar influenced the mean distance between the root and the maxillary sinus in the other premolar. In 25 situations with the first premolar missing, the mean distance between the second premolar and the maxillary sinus was greater compared with when both premolars were present. Because only 4 second premolars (16\%) had migrated anteriorly into the position of the

TABLE 10. Frequency Analysis of the Root Position of the Second Premolars with Respect to the Border of the Maxillary Sinus

\begin{tabular}{|c|c|c|c|c|c|c|}
\hline & \multicolumn{2}{|c|}{$\begin{array}{l}\text { Sagittal } \\
\text { plane* }\end{array}$} & \multicolumn{2}{|c|}{$\begin{array}{l}\text { Coronal } \\
\text { plane* }\end{array}$} & \multicolumn{2}{|c|}{$\begin{array}{l}\text { Axial } \\
\text { plane }\end{array}$} \\
\hline & $N$ & $\%$ & $N$ & $\%$ & $\boldsymbol{N}$ & $\%$ \\
\hline \multicolumn{7}{|l|}{ Buccal roots } \\
\hline $\begin{array}{l}\text { Root tip below/outside } \\
\text { border of MS }\end{array}$ & 111 & 93.2 & 111 & 94.1 & 81 & 89 \\
\hline Root tip at border of MS & 4 & 3.4 & 4 & 3.4 & 3 & 3.3 \\
\hline $\begin{array}{l}\text { Root tip above/inside } \\
\text { border of MS }\end{array}$ & 4 & 3.4 & 3 & 2.5 & 7 & 7.7 \\
\hline Total & 119 & 100 & 118 & 100 & 91 & 100 \\
\hline \multicolumn{7}{|l|}{ Palatal roots } \\
\hline $\begin{array}{l}\text { Root tip below/outside } \\
\text { border of MS }\end{array}$ & 19 & 76 & 18 & 78.3 & 19 & 86.4 \\
\hline Root tip at border of MS & 3 & 12 & 3 & 13 & 0 & 0 \\
\hline $\begin{array}{l}\text { Root tip above/inside } \\
\text { border of MS }\end{array}$ & 3 & 12 & 2 & 8.7 & 3 & 13.6 \\
\hline Total & 25 & 100 & 23 & 100 & 22 & 100 \\
\hline
\end{tabular}

MS, maxillary sinus.

*The distribution of the percentages comparing the buccal and palatal roots was statistically significantly different in the sagittal plane $(P=.02)$ and the coronal plane $(P=.02)$. 
TABLE 11. Overview of Studies (in chronologic order) Assessing Root Positions Relative to the Floor of the Maxillary Sinus

\begin{tabular}{|c|c|c|c|c|}
\hline Authors & Study material & Methodology & Metric measurements & Evaluated teeth \\
\hline Eberhardt et al, 1992 (12) & 38 patients & $\begin{array}{l}\text { CT (sites were examined in } \\
\text { sagittal, coronal, and } \\
\text { axial planes) }\end{array}$ & $\begin{array}{l}\text { Yes (distance from root } \\
\text { to sinus floor) }\end{array}$ & $\begin{array}{l}\text { First premolars through } \\
\text { to second molars }\end{array}$ \\
\hline Kwak et al, 2004 (13) & $\begin{array}{l}33 \text { sides of hemi- } \\
\text { sectioned cadaver } \\
\text { heads }\end{array}$ & $\begin{array}{l}\text { Demineralized maxillae } \\
\text { were sectioned } \\
\text { through long axis } \\
\text { of teeth and scanned } \\
\text { images were analyzed }\end{array}$ & $\begin{array}{l}\text { Yes (distance from root } \\
\text { to sinus floor and from } \\
\text { root to appropriate } \\
\text { cortical plate) }\end{array}$ & $\begin{array}{l}\text { First premolars through } \\
\text { to second molars }\end{array}$ \\
\hline Ariji et al, 2006 (4) & 120 patients & CT (axial plane) & $\begin{array}{l}\text { No (horizontal root } \\
\text { positions within } \\
\text { alveolar process) }\end{array}$ & $\begin{array}{l}\text { First and second molars } \\
\text { only }\end{array}$ \\
\hline $\begin{array}{l}\text { Sharan and Madjar, } \\
2006 \text { (11) }\end{array}$ & 80 patients & $\begin{array}{l}\text { Comparison of panoramic } \\
\text { radiography and CT } \\
\text { (coronal plane) }\end{array}$ & $\begin{array}{l}\text { No (qualitative } \\
\text { classification of vertical } \\
\text { root position relative to } \\
\text { sinus floor) }\end{array}$ & $\begin{array}{l}\text { Second premolars, first } \\
\text { and } \\
\text { second molars }\end{array}$ \\
\hline Howe, 2009 (14) & $\begin{array}{l}37 \text { human cadaver } \\
\text { maxillae with } 69 \\
\text { first molars }\end{array}$ & $\begin{array}{l}\text { Comparison of CBCT and } \\
\text { gross dissection } \\
\text { (coronal } \\
\text { plane) }\end{array}$ & $\begin{array}{l}\text { Yes (minimum distance } \\
\text { from root to sinus floor } \\
\text { and from root to } \\
\text { appropriate cortical } \\
\text { plate) }\end{array}$ & First molars only \\
\hline Kilic et al, 2010 (15) & 92 patients & СBCT (coronal plane) & $\begin{array}{l}\text { Yes (minimum distance } \\
\text { from root to sinus floor) }\end{array}$ & $\begin{array}{l}\text { First premolars through } \\
\text { to third molars }\end{array}$ \\
\hline $\begin{array}{l}\text { Georgescu et al, } \\
2012(16)\end{array}$ & 51 patients & $\begin{array}{l}\text { Comparison of CBCT } \\
\text { (panoramic and } \\
\text { cross sections) and } \\
\text { panoramic radiography }\end{array}$ & $\begin{array}{l}\text { Yes (distance from root to } \\
\text { sinus floor) }\end{array}$ & $\begin{array}{l}\text { First premolars* through } \\
\text { to second molars }\end{array}$ \\
\hline Jung and Cho, 2012 (17) & 83 patients & $\mathrm{CBCT}$ (coronal plane) & $\begin{array}{l}\text { Yes (distance from root } \\
\text { to sinus floor and } \\
\text { horizontal distance to } \\
\text { appropriate cortical } \\
\text { plate) }\end{array}$ & First and second molars \\
\hline Pagin et al, 2013 (18) & 50 patients & $\begin{array}{l}\text { СBCT (sagittal, coronal } \\
\text { and axial planes) }\end{array}$ & $\begin{array}{l}\text { No (qualitative } \\
\text { classification of vertical } \\
\text { root position relative to } \\
\text { sinus floor) }\end{array}$ & $\begin{array}{l}\text { First premolars through } \\
\text { to third molars }\end{array}$ \\
\hline Present study & 192 patients & $\begin{array}{l}\text { СBCT (sagittal, coronal } \\
\text { and axial planes) }\end{array}$ & $\begin{array}{l}\text { Yes (minimum distance } \\
\text { from root to sinus } \\
\text { border) }\end{array}$ & $\begin{array}{l}\text { First and second } \\
\text { premolars }\end{array}$ \\
\hline
\end{tabular}

CBCT, cone-beam computed tomography; CT, computed tomography.

*Only premolars with fused roots were assessed.

first premolar, the anterior position of the second premolar could only partly explain those findings. The opposite was found in the first premolar when the second premolar was missing with shorter mean distances between the first premolar and the maxillary sinus. Removal, loss, or agenesis of the second premolar may have either resulted in an expansion of the maxillary sinus or a more anterior position of the first molar, accounting for the closer position of the maxillary sinus floor to the first premolar. An issue not addressed in the present study was whether subjects had any history of orthodontic treatment. External root resorption (blunting) caused by orthodontics may also affect the measured distances from root surfaces to the border of the maxillary sinus.

\section{Conclusions}

The following conclusions regarding the proximity of premolar roots to the maxillary sinus can be drawn from this CBCT-based investigation:

1. Palatal roots of first premolars were always located closer to the maxillary sinus than buccal roots (irrespective of the CBCT plane)

2. Roots of second premolars were, on average, positioned much closer to the maxillary sinus than roots of first premolars

3. Protrusion of roots inside the maxillary sinus was rare in first premolars and low in second premolars
4. Sex, age, side, and absence of 1 premolar failed to have a significant effect on the mean distance between premolar roots and the border of the maxillary sinus

5. If the distance between premolar roots and the maxillary sinus appears to be critical, taking a CBCT scan is suggested for diagnosis, treatment planning, and surgical intervention.

\section{Acknowledgments}

The authors thank Lukas Martig, Institute of Mathematical Statistics and Actuarial Science, University of Bern, Bern, Switzerland, for his assistance during the statistical analysis.

The authors deny any conflicts of interest related to this study.

\section{References}

1. Punwutikorn J, Waikakul A, Pairuchvej V. Clinically significant oroantral communications — a study of incidence and site. Int J Oral Maxillofac Surg 1994;23:19-21.

2. Oberli K, Bornstein MM, von Arx T. Periapical surgery and the maxillary sinus: radiographic parameters for clinical outcome. Oral Surg Oral Med Oral Pathol Oral Radiol Endod 2007;103:848-55.

3. Nedbalski TR, Laskin DM. Use of panoramic radiography to predict possible maxillary sinus membrane perforation during dental extraction. Quintessence Int 2008; 39:661-4.

4. Ariji Y, Obayashi N, Goto M, et al. Roots of the maxillary first and second molars in horizontal relation to alveolar cortical plates and maxillary sinus: computed tomography assessment for infection spread. Clin Oral Investig 2006;10:35-41. 
5. Bornstein MM, Wasmer J, Sendi P, et al. Characteristics and dimensions of the Schneiderian membrane and apical bone in maxillary molars referred for apical surgery: a comparative radiographic analysis using limited cone beam computed tomography. J Endod 2012;38:51-7.

6. Lu Y, Liu Z, Zhang L, et al. Associations between maxillary sinus mucosal thickening and apical periodontitis using cone-beam computed tomography scanning: a retrospective study. J Endod 2012;38:1069-74.

7. Phothikhun S, Suphanantachat S, Chuenchompoonut V, Nisapakultorn K. Conebeam computed tomographic evidence of the association between periodontal bone loss and mucosal thickening of the maxillary sinus. J Periodontol 2012;83: 557-64.

8. Shanbhag S, Karnik P, Shirke P, Shanbhag V. Association between periapical lesions and maxillary sinus mucosal thickening: a retrospective cone-beam computed tomographic study. J Endod 2013;39:853-7.

9. Sharan A, Madjar D. Maxillary sinus pneumatization following extractions: a radiographic study. Int J Oral Maxillofac Implants 2008;23:48-56.

10. Jun BC, Song SW, Park CS, et al. The analysis of maxillary sinus aeration according to aging process; volume assessment by 3-dimensional reconstruction by highresolutional CT scanning. Otolaryngol Head Neck Surg 2005;132:429-34.

11. Sharan A, Madjar D. Correlation between maxillary sinus floor topography and related root position of posterior teeth using panoramic and cross-sectional computed tomography imaging. Oral Surg Oral Med Oral Pathol Oral Radiol Endod 2006;102:375-81.

12. Eberhardt JA, Torabinejad M, Christiansen EL. A computed tomographic study of the distances between the maxillary sinus floor and the apices of the maxillary posterior teeth. Oral Surg Oral Med Oral Pathol 1992;73:345-6.

13. Kwak HH, Park HD, Yoon HR, et al. Topographic anatomy of the inferior wall of the maxillary sinus in Koreans. Int J Oral Maxillofac Surg 2004; $33: 382-8$.
14. Howe RB. First molar radicular bone near maxillary sinus: a comparison of CBCT analysis and gross anatomic dissection for small bony measurement. Oral Surg Oral Med Oral Pathol Oral Radiol Endod 2009;108:264-9.

15. Kilic C, Kamburoglu K, Yuksei SP, Ozen T. An assessment of the relationship between the maxillary sinus floor and the maxillary posterior teeth root tips using dental cone-beam computerized tomography. Eur J Dent 2010;4:462-7.

16. Georgescu CE, Rusu MC, Sandulescu M, et al. Quantitative and qualitative bone analysis in the maxillary lateral region. Surg Radiol Anat 2012;34:551-8.

17. Jung $\mathrm{YH}$, Cho BH. Assessment of the relationship between maxillary molars and adjacent structures using cone beam computed tomography. Imaging Sci Dent 2012;42:219-24.

18. Pagin O, Centurion BS, Rubira-Bullen IR, Alvares Capelozza AL. Maxillary sinus and posterior teeth: accessing close relationship by cone-beam computed tomographic scanning in a Brazilian Population. J Endod 2013;39:748-51.

19. Brunner E, Domhof S, Langer F. Nonparametric Analysis of Longitudinal Data in Factorial Experiments. New York: Wiley; 2002.

20. Hirata Y, Kino K, Nagaoka S, et al. A clinical investigation of oro-maxillary sinus perforation due to tooth extraction (article in Japanese). Kokubyo Gakkai Zasshi 2001;68:249-53.

21. Kim HJ, Yoon HR, Kim KD, et al. Personal-computer-based three-dimensional reconstruction and simulation of maxillary sinus. Surg Radiol Anat 2002;24:393-9.

22. Kopecka D, Simunek A, Brazda T, et al. Relationship between subsinus bone height and bone volume requirements for dental implants: a human radiographic study. Int J Oral Maxillofac Implants 2012;27:48-54.

23. Gosau M, Rink D, Driemel 0, Draenert FG. Maxillary sinus anatomy: a cadaveric study with clinical implications. Anat Rec 2009;292:352-4.

24. Sahlstrand-Johnson P, Jannert M, Strömbeck A, Abul-Kasim K. Computed tomography measurements of different dimensions of maxillary and frontal sinuses. BMC Med Imaging 2011;11:8. 